\title{
HYBRIDISM - THEORETICAL LEARNING RESPONSE TO THE GROWING DIVERSITY IN HIGHER EDUCATION
}

\author{
Christian-Andreas Schumann, Anna-Maria Nitsche, West Saxon University of Zwickau,
} Kevin Reuther, University of Leipzig, Claudia Tittmann, West Saxon University of Zwickau, Germany

\section{Abstract}

The transition from a knowledge society to a network society leads to growing globalisation, networking and a sudden increase in networked knowledge. Higher education and further education, like vocational training, must react with hybrid forms of generalisation and specialisation, in which way complexity and diversity are rapidly increasing in the education systems. In addition, digitalisation and the consequences of the pandemic are pushing this development. Hybridisation can make a theoretical and practical contribution to finding an answer to the complexity of mastering these processes. The consistent further development of learning theory approaches in the context of modelling and applying hybrid systems and automata leads to hybridism and thus to the expansion of the spectrum of learning theories.

\section{Introduction}

Human existence relates to perceiving and recognizing the environment. The question of how to recognize objective reality is of existential importance (Audi, 2010). Signals are based on stimuli. They describe changes of state that serve a communication or information purpose and can trigger behavioural consequences or reactions (Hoffmeister \& Ziegler, 2021). The process of acquiring and changing behaviours and cognitive structures, consciously or unconsciously, is called learning. In this process, knowledge, skills, and abilities are acquired, and feelings, behaviours and ways of thinking are formed in combination of psychological, emotional, social, and physical aspects (Sandweg, 2017).

Building blocks of cognition consist of elements which are subject to certain laws of construction. Structures are self-regulating wholes and consist of a system of elements and relations that can be subjected to transformations. Building blocks of cognition are characterized by groups of schemata that determine how humans typically deal with classes of environmental conditions. Schemata serve to structure knowledge during 
storage, recall, embedding, formation, and representation of knowledge (Rumelhart, 1978). Due to the active confrontation with the environment, which every organism permanently engages in by scanning stimuli and comparing information, it is therefore given per se that humans go through a continuous, lifelong process of learning, independent of the form of learning, the learning method, the learning motivation, the learning technology, etc. The learning theories do not describe whether learning can be shaped or promoted, but rather how it can be inhibited.

Learning is defined as a process that integrates individual and environmental experiences and influences to acquire, enrich, or change knowledge, skills, values, attitudes, behaviours, and worldviews. Learning theories develop hypotheses that describe how this process occurs. Major learning theories include behaviourism, cognitivism, and constructivism, which are complemented and extended by learning concepts such as social constructivism, experiential learning, multiple intelligences, situational learning, and community of practice (UNESCO, 2021).

The current accentuation of relevant learning theories, as described in the UNESCO contribution, testifies to two fundamental tendencies, on the one hand the constant further development and diversification of the body of theories and on the other hand the generation of new theories which, like connectivism, take account of new and contemporary forms of teaching and learning in reality. High interconnectedness and networking through globalization and digitalization were the impetus for a new theoretical consideration of learning, but also growing complexity and diversity of influences on learning in the form of multiple hybrid dimensions will be reflected in theory and practice.

\section{Issue of growing complexity and diversity}

The development of science is closely connected with the concept of holism, documented, for example, by Aristotle's statement that the whole is more than the sum of its parts. Moreover, in this context, he discussed aspects of diversity and hybridity in his work "The Metaphysics”, which are obviously related to holistic approaches (McMahon, 2008).

The holistic approach is becoming more and more established in the systematic analysis and systematic design of various fields of knowledge, including education. If large educational systems are considered with their interactions with other social systems, the multitude of objects and relations involved leads to so-called large systems with an extremely high complexity. To better manage this complexity, decompositions are used to break down the whole into smaller units. The sectional view through decomposition generates simplifications and thus better controllability, but also limitations regarding the model quality. 
Despite this pragmatic approach, the fact remains that complexity exists in reality. Oversimplifications lead to inaccurate statements, which is why the realisation that a holistic approach is necessary to guarantee the reflection of real conditions in a corresponding quality is becoming more and more accepted. The increasing emphasis on interdisciplinary and transdisciplinary approach and the demand for the growing number of professional competences further increase the complexity (Schumann et al., 2019). The change of educational systems in the sense of holistic and systemic approaches reflects the changes of real systems in society in general and in education in particular (Heidling et al., 2019).

The volume of information and knowledge is growing exponentially, from the industrial society to the knowledge society to the network society. They are transferred and made available in ever greater quantity and density, but the half-life of their topicality is continuously decreasing. The learning process is becoming a lifelong process with many different types of learning objects, knowledge transfer methods, means and methods in combination with multimedia and computer-based information systems as a highly complex network for mastering knowledge transfer and adequate learning processes (Schumann, Tittmann, \& Tittmann, 2008).

Since education always reflects real systems in essential elements, the transfer of these insights leads to analogous challenges in the content-related, organisational, and structural design of new globalised and diversified offerings in higher education. Diversity characterises the variety, manifoldness, and multiplicity of objects and relationships, processes, and functions as well as actors and roles in learning in social groups. Diversity is thus an organisational principle. It is part of any organisational development, especially its strategic orientation. Four strategies are essential to the overarching vision, mission, and strategy of the organisation, which determine the aspirations of diversity management: Managing Representation, Managing Demographic Relationships, Managing Diverse Talents and Managing All Strategic Diversity Mixes (Roosevelt, 2010).

Digitalisation and globalisation reinforce the trend towards diversification. Digital technologies and digital products enable more virtual mobility and access to appropriate digital offerings. This process is accelerated by learners' interactions in social networks. This creates increasing pressure for diversification on the supply side to help satisfy growing individualisation on the demand side. The multiple choices, in turn, increase the individual pressure for learners to make decisions. They are in constant exchange with other actors to choose the best offer without necessarily entering a rigid commitment to one or more educational organisations (Schumann et al., 2019). 


\section{Focus on hybridisation in higher education}

Hybridisation has always been part of the development of learning forms and methods. This is due to the generality of the term hybridity. It was originally used in biology and botany, but later transferred to cultural phenomena also in the context of innovation and creativity (Canan, 2015).

Since, in turn, cultural aspects are related to all other areas of society, including education, and thus learning, it is used in different contexts nowadays. The concept of hybrid states was adapted within the framework of systems theory and is thus not only relevant in biological, social, and cultural terms, but is used in all areas that can be considered by means of systems theory approaches. Either two originally separate manifestations of different systems or two manifestations of a system are combined in such a way that different hybrid forms are created.

Hybrid forms of teaching, learning and assessment in the interplay of face-to-face and distance learning have been in vogue since the appearance of distance learning several decades ago. This trend has been further strengthened by the possibilities of online learning. However, this is already an overlap of two hybrid forms, which in turn can also be combined with each other: Face-to-face teaching and distance learning as well as offline and online learning. A hybrid form of face-to-face and distance learning is possible, whereby the respective proportion can usually be adjusted as desired and can in turn be combined with a hybrid form of offline and online learning, whose proportions can also vary between two poles. These models have been developed and discussed in the professional world for many years (Doering, 2006; Horn, Crouser, \& Bers, 2012).

Its importance has increased enormously with the worldwide, extensive transition from face-to-face to internet-based distance education in the context of the measures to cope with the Corona pandemic. Integration and complementarity of face-to-face and distance education in this context are discussed and analysed worldwide and lead to new approaches of educational strategic concepts and up to educational policy. However, it is not a pure opposition of face-to-face and distance education. The hybrid system is not reduced to one or two hybrid forms of learning, but rather already discussed in the context of other aspects that may well be hybrid in nature, such as educational platforms, individual and group work, special teaching and learning methods, competences to be developed, teaching materials, human resources, etc. (Opertti, 2021 February).

It follows inevitably from these considerations that a stronger emphasis on the holistic nature of educational strategy concepts is called for. It is emphasised that any kind of onedimensional or disciplinary approach misses the reality of what learners will demand and need from new forms of teaching and learning in the future. The digital transformations 
that are increasingly triggering these changes are multi-layered in nature and not only technology driven. There are already many forms in the areas of teaching material, learning planning, type of learning, etc. that can take on different hybrid states for the benefit of the learners or can be adjusted accordingly (Opertti, $2021 \mathrm{March}$ ).

Complex investigations lead to hybrid systems in education, for example, hybrid learning configurations, hybridity in learning spaces, hybrid learning courses, hybridity in recognition management, hybrid study programmes, hybrid home study, etc. What they all have in common are holistic investigations that establish the connection between complexity, diversity, and hybridity (Cremers \& et al., 2017; Cook, Mor, \& Santos, 2020; Olapiriyaku \& Scher, 2006; Kislova, 2019; Schumann \& et al., 2016; van der Merwe \& Schoonwinkel, 2019; Schumann \& et al., 2019).

\section{Hybridism as complementary learning theory}

In principle, a learning theory must meet the requirements that are placed on theories in general. The special feature is the description of how knowledge can be transferred from one person to another or how knowledge can be gained from the confrontation with the environment. This requires a set of models and concepts that serve as a theoretical whole to systematically observe, analyse, describe, explain, and interpret learning and its peripheral processes. The construction of a learning theory is an attempt to classify knowledge about learning. Learning theories support a conceptual framework vocabulary for arriving at interpretations and understanding through observations. The dominant, classical learning theories are behaviourism, cognitivism, and constructivism. In the age of digitalisation, connectivism has been developed as another learning theory that puts the mentioned classical learning theories into a new context based on the digital networking of learners and knowledge (Duke, Harper, \& Johnston, 2013).

From an eclectic view, there is a re-evaluation of classical learning theories and the formulation of a new theory that places learning in the context of digitalised knowledge networks and educational systems. Connectivism was developed among several other learning theories, but now occupies a prominent position alongside classical learning theories. It includes elements of chaos theory, self-organisation, and network theory. Individual and organisational learning in knowledge networks with corresponding nodes and connections is placed at the centre of theoretical considerations. Free, network-based access to knowledge resources for the purpose of learning is propagated and theoretically founded (Siemens, 2005).

Through the development of connectivism theory, limits of traditional learning theories are shown, but at the same time new limits are set in a networked world through the uncontrolled access to information and knowledge in learning. The debate about whether 
connectivism is a pedagogical approach rather than a learning theory is explained by the fact that learning is placed in a new network-based context. But connectivism addresses learning processes per se, which makes it at least a learning theory derived from what exists (Kop \& Hill, 2008).

The challenge of the growing complexity of the body of knowledge and the increasing number of access points for learners must be met, whereby the use of taxonomy for class formation in education opens the way to better systematisation (Anderson et al., 2001).

This approach can be further developed in terms of systems theory with the integration of object orientation, whereby states of systems, subsystems, objects, attributes, or attribute values are taken as a basis. These states are mapped independently of the object class via dimensions that can be used to describe hybrid states during learning (Rühling et al., 2010).

The learning process is considered primary, as in all learning theories. The process elements, objects or properties of the objects are understood as dimensions and can assume either continuously or discretely defined states within defined boundaries. Each dimension associated with the learning process can thus assume a hybrid state. Any number of hybrid dimensions can be combined. The resulting hybridity of the entire knowledge transfer system and the associated learning processes allows the derivation of a learning theory, hybridism. The approach can now be pursued to map the interaction of the dimensions by means of hybrid systems and automata (Ábrahám, 2012).

However, automata are also the prerequisite for the controllability and regularability of processes. In the special case of learning processes, a hybrid system would therefore help to model learning in highly complex knowledge networks, as they are increasingly characteristic of the network society, in such a way that the learning processes can be controlled or regulated.

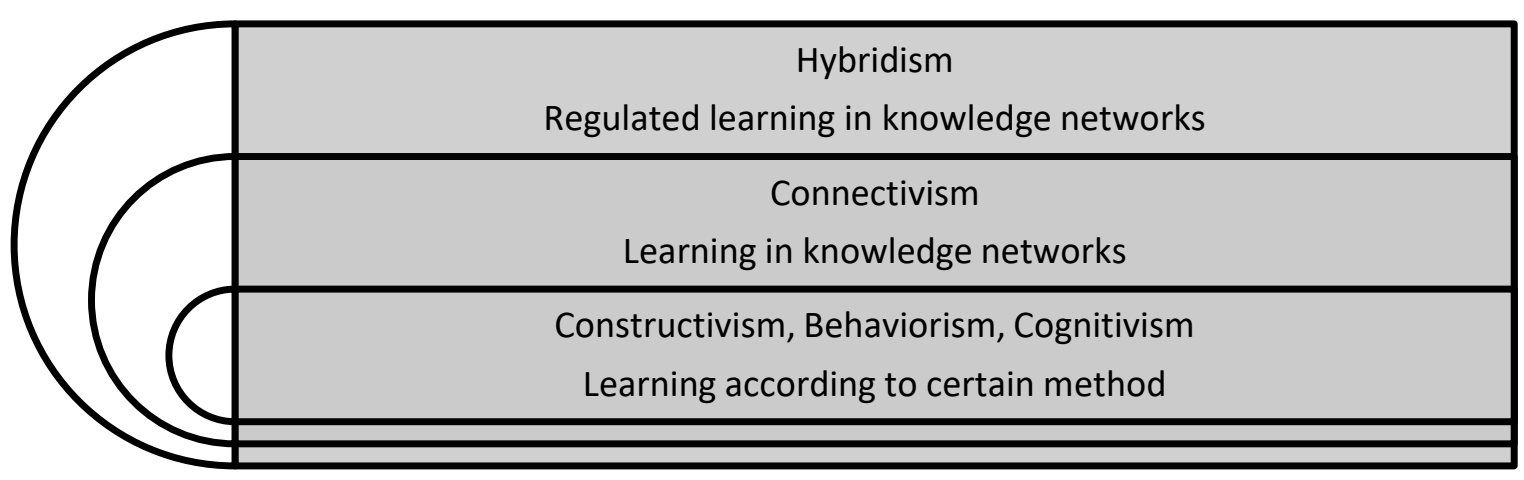

Figure 4. Learning theories and their causal classification in an overall context

The contribution that can be made by expanding the set of learning theory approaches using hybridism is the multidimensional description of hybrid states in modelling learning processes within the framework of single knowledge bases or knowledge networks. 
Individuals learn in a system of one to several, hybrid dimensions to expand their knowledge and experience as well as to be able to conclude how to change their behaviour. In addition, there is the option not only to organise their learning process themselves in a multi-talented and networked world of knowledge, but also to actively influence the absorption of information and knowledge as well as the resulting possible change in behaviour by actively influencing hybrid learning space dimensions by changing their states individually or for social groups. Teachers also have the possibility to optimise learning processes of third parties by providing prefabricated, optimised sets of the setting of hybrid states of the dimensions or by learning process-accompanying changes of the hybrid states of the dimensions for individuals or groups of individuals.

\section{Conclusions and outlook}

Hybridism integrates self-determination, networking, and multi-dimensionality of changeable variables in stationary or networked learning spaces for learning processes and thus determines how learners acquire knowledge and experience or modify their behaviour in a self-directed, externally directed or uncontrolled way, also in combination. The type and quantity of the dimensions involved as well as their possible hybrid states are defined and optimised in relation to the goals of learning, thus enabling learnercentredness, objectification and self-control in highly complex and networked systems of knowledge transfer. Through the permanent possibility of changing the setting of the hybrid states of the dimensions as well as the combination of the dimensions, learning processes can be made dynamic and adaptively controllable. Theoretical preliminary work on hybrid systems and automata can be used for modelling hybrid learning processes.

In the future, natural and artificial intelligence will not only complement each other, but rather work together collaboratively. In smart systems, influencing variables are combined multi-dimensionally. They can be hybridised in their states and modified to influence the behaviour of the system. It will be interesting to see what potentials can be tapped through convergence and adaptation of the learning processes between natural and artificial objects and systems through hybridisation.

\section{References}

Ábrahám, E. (2012). Modeling and Analysis of Hybrid Systems. Lecture Notes. Theory of Hybrid Systems. Faculty of Mathematics, Computer Science, and Natural Sciences. Aachen: RWTH Aachen University.

Anderson, L. W., Krathwohl, D. R., Airasian, P. W., et al. (2001). A Taxonomy for Learning, Teaching, and Assessing: A Revision of Bloom's Taxonomy of Educational Objectives. Abridged Edition. New York: Longman. 
Audi, R. (2010). Epistemology: A Contemporary Introduction to the Theory of Knowledge $\left(3^{\text {rd }}\right.$ ed.). New York and London: Routledge.

Canan C. (2015). Was ist Hybridität? In Identitätsstatus von Einheimischen mit Migrationshintergrund, 51. Wiesbaden: Springer.

Cook, J., Mor, Y., \& Santos, P. (2020) Three cases of hybridity in learning spaces: Towards a design for a Zone of Possibility. British Journal of Educational Technology, 51(4), 1155-1167.

Cremers, P. H. M., Wals, A. E. J., Wesselink, R., \& Mulder, M. (2017). Utilization of design principles for hybrid learning configurations by interprofessional design teams. Instructional Science, 45(2), 289-309.

Doering, A. (2006) Adventure Learning: Transformative hybrid online education. Distance Education, 27(2), 197-215. New York and London: Routledge.

Duke, B., Harper, G., \& Johnston, M. (2013). Connectivism as a digital age learning theory. The International HETL Review, Special Issue 2013, 4-13.

Heidling, E., Meil, P., Neumer, J., et al. (2019). Ingenieure und Ingenieurinnen für Industrie 4.0. Studie des Institutes für sozialwissenschaftliche Forschung. 15-70. München: Institutes for social science research.

Hoffmeister, H., \& Ziegler, C. (2021). Freies Lehrbuch der Biologie. Chapter 05. GNU Free Documentation License Version 1.3. Retrieved March 26, 2021, from https://hoffmeister.it/index.php/biologiebuch

Horn, M. S., Crouser, R. J., \& Bers, M. U. (2012). M.U. Tangible interaction and learning: the case for a hybrid approach. Personal and Ubiquitous Computing, 16, 379-389. Springer Nature. https://doi.org/10.1007/s00779-011-0404-2

Kislova, A. (2019). Hybrid Homework - Blending Blended Learning and Face to Face in four Undergraduated Programmes. In M. Brown, M. Nic Giolla Mhichil, E. Beirne, \& E. Costello (Eds.), Proceedings of the 2019 ICDE World Conference on Online Learning (Vol. 1, pp. 511-520). Dublin: Dublin City University.

Kop, R., \& Hill, A. (2008). Connectivism: Learning theory of the future or vestige of the past? International Review of Research in Open and Distance Learning, 9(3).

McMahon, J. H. (2008). The Metaphysics. Aristotle translated by McMahon. New York: Cosimo Classics. 
van der Merwe, A., \& Schoonwinkel, A. (2019). Student Access and Success through Hybrid Learning: A South African University's Business and Delivery Model. In M Brown, M. Nic Giolla Mhichil, E. Beirne, \& E. Costello (Eds.), Proceedings of the 2019 ICDE World Conference on Online Learning (Vol. 1, pp. 981-989). Dublin: Dublin City University.

Olapiriyaku, K., \& Scher, J. M. (2006). A guide to establishing hybrid learning courses: Employing information technology to create a new learning experience, and a case study. The Internet and Higher Education, 9(4), 287-301.

Opertti, R. (2021, February). Ten clues for rethinking curriculum. In-Progress Reflection No. 42. IBE/2021/WP/CD/42. 17-18. Geneva: UNESCO International Bureau of Education.

Opertti, R. (2021, March). Education in a post-COVID world: Additional considerations. No. 43. IBE/2021/WP/CD/43. 13-14. Geneva: UNESCO International Bureau of Education.

Roosevelt, Th. (2010). World Class Diversity Management. San Francisco: Berrett-Koehler Publishers.

Rühling, S., Schumann, C.-A., et al. (2010). Typology and Illustration of Generic Competencies in a Hybrid Learning Environment. In A. Szücs, \& A.W. Tait (Eds.), Media Inspirations for Learning. e-Proceedings: EDEN 2010 Annual Conference, Valencia. Budapest: European Distance and E-Learning Network.

Rumelhart, D. E. (1978). Schemata: The Building Blocks of Cognition. Volume 79 of Technical report. University of California, San Diego. Center for Human Information Processing.

Sandweg, K. (2017, July 14). Lerntheorien: Wie lernen wir eigentlich? CogniFit [Blog post]. Retrieved March 20, 2021, from https://blog.cognifit.com/de/lerntheorien/

Schumann, Chr.-A., Marr, R., Mißbach, P., \& Weber, J. (2016). Recognition Management for promoting and accelerating the academic careers of professional learners. GUIDE Journal "Digital Universities: International Best Practices and Applications" ISSUE, 2016(1), 3-16.Roma: GUIDE Association.

Schumann, C.-A. et al. (2019). Key role of modularization for new global pathways expanding access to multiple study programs. In M. Brown, M. Nic Giolla Mhichil, E. Beirne, \& E. Costello (Eds.), Proceedings of the 2019 ICDE World Conference on Online Learning (Vol. 1, pp. 833-845). Dublin: Dublin City University. 
Schumann, C.-A., Tittmann, C., \& Tittmann, S. N., (2008). Merger of Knowledge Network and Users Support for Lifelong Learning Services. In Learning to Live in the Knowledge Society (pp. 149-152). Springer: Boston.

Siemens, G. (2005). Connectivism: A learning theory for the digital age. International Journal of Instructional Technology and Distance Learning, 2(1), 3-10.

UNESCO. (2021). Most influential theories of learning. General Education System Quality Analysis/Diagnosis Framework (GEQAF). Retrieved March 23, 2021, from http://www.ibe.unesco.org/en/geqaf/annexes/technical-notes/most-influentialtheories-learning 